\title{
A Basic Wind Speed Map for Oman
}

\author{
A.S. Alnuaimi ${ }^{a}$, M.A. Mohsin ${ }^{b}$ and K.H. Al-Riyamic \\ a Department of Civil \& Architectural Engineering, Sultan Qaboos University, POB 33, PC 123, Muscat, Oman \\ ${ }^{b}$ Department of Civil and Architectural Engineering, College of Engineering, University of Buraimi, PO Box 890, Buraimi \\ 512, Oman. \\ c Senior Structural Engineer, Central Design Office, Royal Court Affairs, PO Box 949, Muscat 100, Oman.
}

Received 17 May 2014; accepted 14 September 2014

\begin{abstract}
The aim of this research was to develop the first basic wind speed map for Oman. Hourly mean wind speed records from 40 metrological stations were used in the calculation. The period of continuous records ranged from 4-37 years. The maximum monthly hourly mean and the maxima annual hourly mean wind speed data were analysed using the Gumbel and Gringorten methods. Both methods gave close results in determining basic wind speeds, with the Gumbel method giving slightly higher values. Due to a lack of long-term records in some regions of Oman, basic wind speeds were extrapolated for some stations with only short-term records, which were defined as those with only 48 years of continuous records; in these cases, monthly maxima were used to predict the long-term basic wind speeds. Accordingly, a basic wind speed map was developed for a 50-year return period. This map was based on basic wind speeds calculated from actual annual maxima records of 29 stations with at least 9 continuous years of records as well as predicted annual maxima wind speeds for 11 short-term record stations. The basic wind speed values ranged from 16 meters/second $(\mathrm{m} / \mathrm{s})$ to $31 \mathrm{~m} / \mathrm{s}$. The basic wind speed map developed in this research is recommended for use as a guide for structural design in Oman.
\end{abstract}

Keywords: Oman, Basic wind speed, Basic wind speed map, Weather stations.

$$
\begin{aligned}
& \text { خريطة سرعة الرياح الأسـاسية لسلطنة عمان } \\
& \text { علي س. النعيهي و محمد أ. المحسن و خالد. ح. الريامي } \\
& \text { الملخص: يهدف هذا البحث ولأول مرة إلى تطوير خريطة سرعة الرياح لعمان. تم استخدام سجلات متوسط سرعة الرياح بِّ. }
\end{aligned}
$$

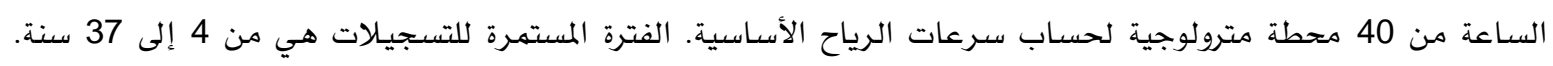

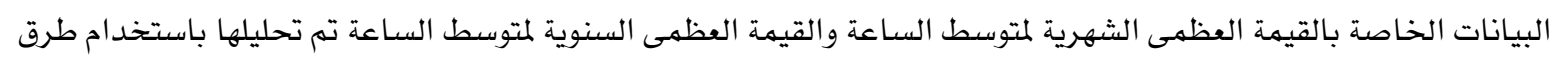

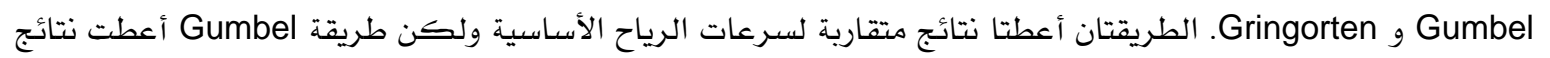

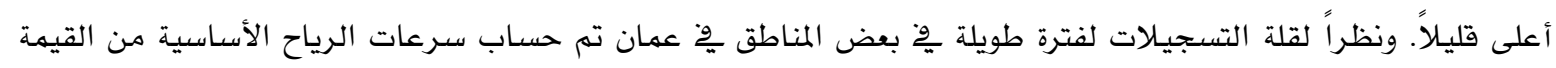

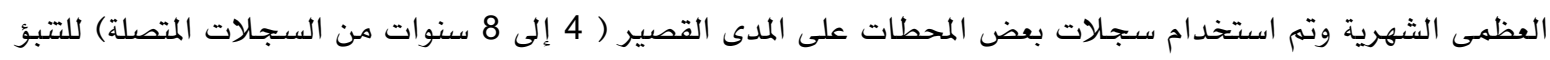

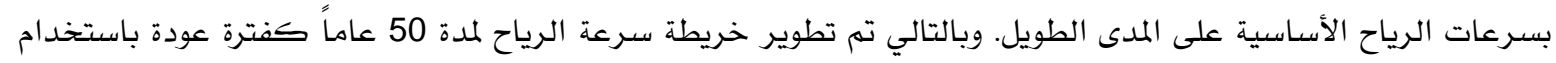

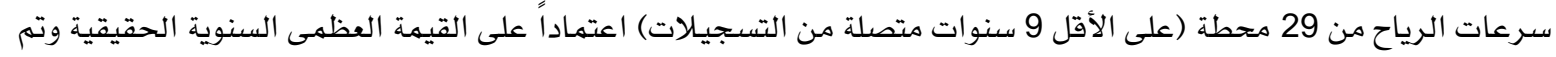

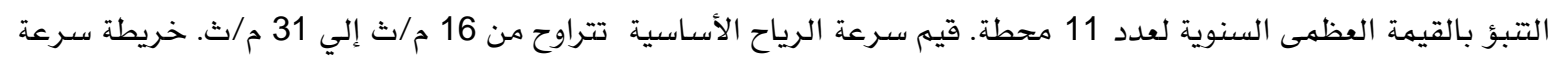

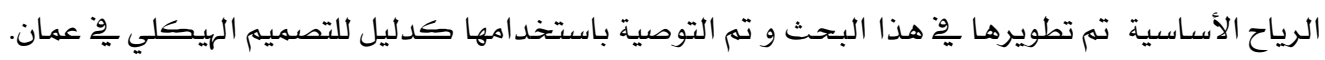

$$
\begin{aligned}
& \text { مفاتيح الكلمات: عمان ، سرعة الرياح الأساسية ، خريطة سرعة الرياح الأساسية ، محطات الطقس. }
\end{aligned}
$$

*Corresponding author's e-mail: alnuaimi@squ.edu.om 


\section{Introduction}

\subsection{Literature Review}

As Oman is not considered a potential earthquake zone, the effects of wind loads on structures are considered the dominant factor when determining lateral loads on edifices such as buildings, chimneys, power transmission towers, and satellite communication towers. Wind speed measurement in Oman is carried out by the Directorate General of Civil Aviation and Meteorology under the Ministry of Transport and Communications. As of the end of 2013, there were 55 meteorological stations throughout the country as shown in Fig. 1. The oldest station, at Muscat International Airport, was constructed in 1977. The stations measure the hourly mean wind speed, an hourly threesecond gust, temperature, precipitation and humidity. Wind speed is measured at a 10 -meter height in open and level ground by cup anemometers whereas wind vanes are used to determine wind direction.

Basic wind speed $\left(V_{b}\right)$ is the wind speed estimated by different methods to be exceeded on average only once in 50 years (Gibbs et al. 1981). Guide to the Use of the Wind Load Provisions of the American Society of Civil Engineers (ASCE) 7-02 (Kishor and Delahay 2004 ) requires a $2 \%$ exceedance probability which equals to a 50-year return period. For crucial facilities such as hospitals, only a $1 \%$ exceedance probability on a 100-year return period is allowed. For structures with a low risk to human life if compromised, an exceedance limit of up to $4 \%$ is allowed. The Minimum Design Loads for Buildings and Other Structures (ASCE/SEI-7-10) requires different exceedance probabilities in a 50-year return period depending on the location and occupancy category of the structure. It uses the three-second gust in the calculation of basic wind speed.

The basic wind speed for the design of buildings in the British Standard, Annex B of the BS6399-2 (1997), depends on the hourly mean wind speed records. The monthly maximum of the hourly mean is used to obtain the annual maxima, which are used to develop basic wind speed maps. The basic wind speed has an annual risk of exceedance of 2\% (a 50-year return period).

Simiu (2009) stated that movement toward international standards appears to justify the use of 10-minute mean speeds, thus conforming to the practice sanctioned by the World Meteorological Organization or of other internationally acceptable measures of sustained wind speeds. A procedure for estimating extreme wind speeds at locations where longterm data are not available was reported by (Simiu et al. 1982; Grigoriu 1984). The method was tested on 67 three-year records in the USA and found to infer the approximate probabilistic behaviour of extreme winds from data consisting of the largest monthly wind speeds recorded over a period of three years or longer. Similarly, (Kramer and Gerhardt 1988) carried out a simulation process to predict extreme wind speed from actual 22 year records. They stated that it is not necessary to have 22 years of continuous records and that even a five-year record is adequate for showing good comparisons between the simulated results and historical data.

Among many statistical methods, the (Gumbel 1958; Gringorten 1963) methods are the most popular statistical methods used in meteorology for calculating basic wind speeds. These methods have been used extensively for analyses of wind speed records in many parts of the world (Dyrbye and Hansen 1999; Holmes 2001). Harris (1996) re-examined Gumbel's extreme value distribution for analysing annual maxima wind speeds or similar data and suggested an interchange of the axes of this method. He proposed an automated procedure that gives exactly the same results. An and Pandy (2005) made a comparison of methods of extreme wind speed estimation. They studied four different methods: Gumbel's method, the modified Gumbel distribution, the peak-overthreshold method and Cook's method of independent storms. These four methods were applied to a common data set consisting of six stations in the USA. They concluded that the standard Gumbel method tends to provide an upper bound estimate of 50/500 year design wind speed, and Cook's method of independent storms estimates of design wind speed exhibits a 


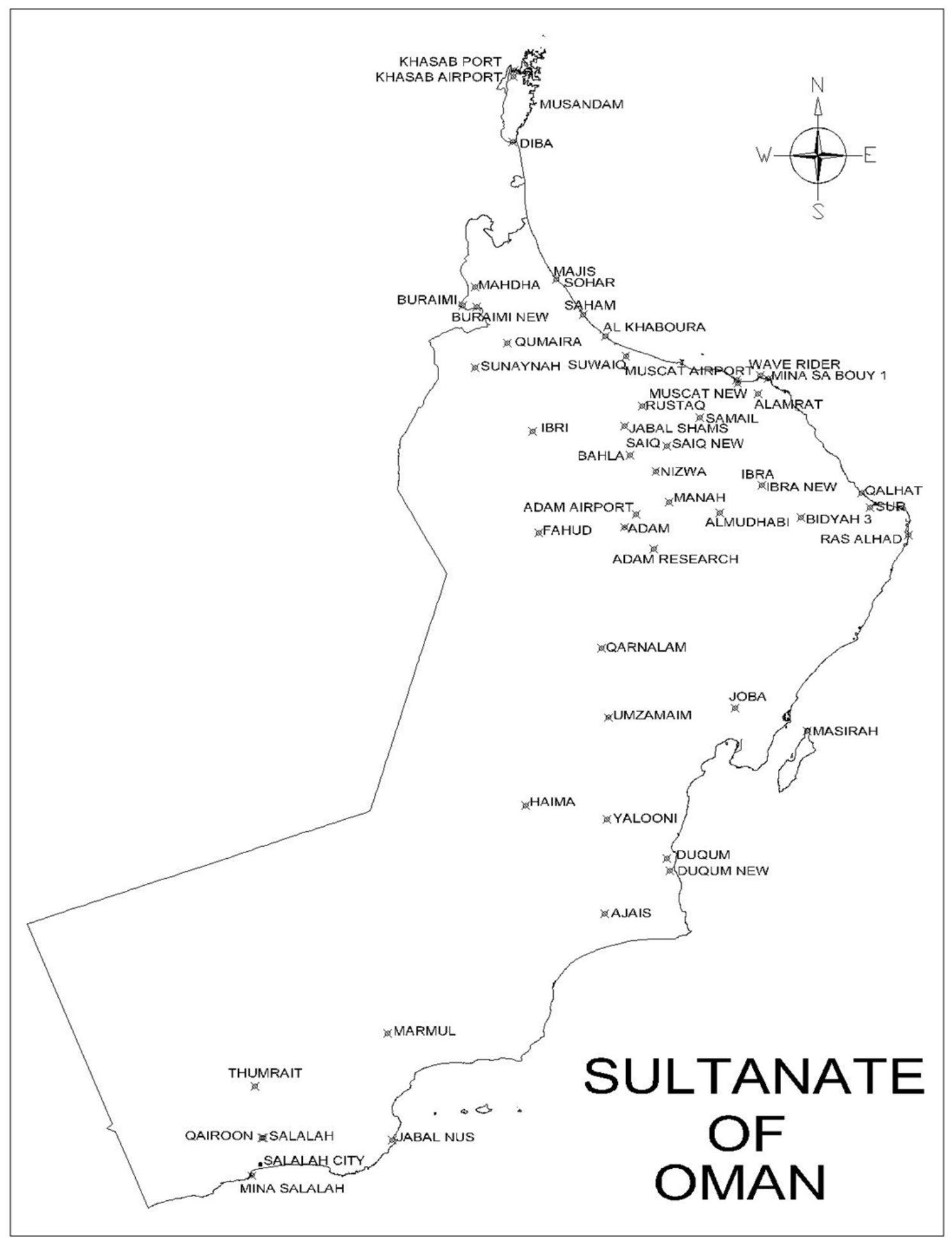

Figure 1. Locations of meteorological stations in Oman (names of stations are as provided by Directorate General of Civil Aviation and Meteorology). 
more stable trend with limited threshold sensitivity, which is in contrast with the rapidly fluctuating estimates obtained from the peaks over threshold methods.

Abohemda and Alshebani (2010) used Gumble's method to predict basic wind speed values for Libya for a 50-year return period from the data of 22 stations. Lakshmana et al. (2009) studied the wind speed data from 70 metrological centres in India and calculated basic wind speeds using Gumbel's approach. Al Maawali et al. (2008) studied wind data from 10 weather stations in Oman. They calculated the basic wind speed using the three-second gust at the locations of 10 stations using the Gumbel and Gringorten methods. They found that both methods yielded similar results. Dorvlo (2002) used the Weibull distribution to model wind speeds at four locations in Oman. The scale and shape parameters were estimated using Pearson's chi-squared test, the method of moments, and the regression method. It was observed that the estimates using the chisquared test gave the best overall fit to the distribution of the wind data. Choi and Tanurdjaja (2002) studied extreme wind estimates in Singapore using Gumbel's method and Cook's method of independent storms. They concluded that the independent storm method and Gumbel's method both gave quite similar results. Kasperski (2002) developed a wind speed map for Germany based on a refined extreme value analysis using high gust wind speeds. He divided the country into four basic wind speed zones ranging from 22.5 meters/second (m/s) to $32.5 \mathrm{~m} / \mathrm{s}$. Akosy et al. (2004) used the wavelet approach to generate hourly mean wind speed data using normal and Weibull probability distribution functions. They concluded that the wavelet approach can be used as an alternate to existing generation methods. Sahin (2003) developed an hourly mean wind speed exceedance map for Turkey using the Gumbel-Lieblein BLUE method. In this research, the Gumbel and Gringorten methods were used for the analysis of hourly mean wind speed records.

\subsection{Problem Statement and Motivation}

Due to the recent extensive development of major cities in Oman, the trend toward building higher and lighter structures has emerged only during the last two decades. Wind load must be taken into consideration during the structural design of high-rise buildings, chimneys, transmission towers, and so on, requiring basic wind speed values. The basic wind speed is determined according to the climatic condition of each region. Before this research, the hourly mean wind speed data collected from 55 metrological stations had not been utilized in the development of a basic wind speed map for Oman and, as of this article's publication, no local unified code or written regulations are available for the design of high-rise buildings. The need for a basic wind speed map that covers different regions of the country has become evident. The aim of this research was to develop a basic wind speed map which can be used as a code guideline or regulation for structural design in Oman.

\subsection{Gumbel Verus Gringorten Method}

Gumbel (1958) developed an easily usable methodology for fitting recorded monthly or annual wind speeds. The ASCE (1991) stated that the Gumbel extreme-value procedure is well accepted by other investigators, including (Simiu et al. 1998). The Gringorten (1963) method is considered a simple modification of Gumbel's extreme-value procedure. The only difference between Gumbel and Gringorten's methods is in the calculation of the probability of non-exceedance $(p)$. The procedure of calculating the basic wind speed is as follows:

Step 1: Data are ranked in ascending order $(1,2$, $3, . ., m$,$) where m$ is the largest value. The total number of readings is called $N$ (ie. number of years).

Step 2: The probability of non-exceedance $(p)$ is determined according to

$$
\begin{aligned}
& \text { Gumbel: } p=\frac{m}{N+1} \\
& \text { Gringorten: } p=\frac{m-0.44}{N+0.12}
\end{aligned}
$$

Step 3: Reduced variant, $y$ is calculated as

$$
\begin{aligned}
& y_{i}=-\ln (-\ln p) \\
& i=\text { record identification number. }
\end{aligned}
$$


Step 4: The data are plotted against the reduced variant, $y$, and a line of best fit is drawn, usually by means of linear regression. Therefore, if the best fitting line $y=a x+u$, then $u=$ the mode of distribution $=$ the intercept of the line and $a=$ the slope of the line (scale factor for $x$ ).

Step 5: For different values of the return period, Eqn. 4 can be used to calculate the basic wind speed,

$V_{b}=u+\frac{1}{a} \ln R$

where $\mathrm{R}=$ return periods in years (eg. 50, 100, etc.) and $V_{\mathrm{b}}=$ basic wind speed in $\mathrm{m} / \mathrm{s}$.

\section{Methodology}

The basic information about Oman's 55 weather stations is given in Table 1 . More than 8,200 records of monthly maximum hourly mean wind speed were obtained from the Directorate General of Civil Aviation and Meteorology in Oman.

Descriptive statistics along with box plot graphs were developed for each station to ensure the homogeneity and independence of raw data, and to exclude extreme outliers. The records were divided into three types: long term, short term and not considered. Long term means stations that have continuous records for at least nine years (29 stations); short term means stations that have continuous records of at least four years and less than nine years (11 stations), and not considered (15 stations) means records are not included in the analysis due to discontinuity of the records (less than four continuous years of records are required to be classified as not considered).

The monthly maximum and the annual maxima of the hourly mean wind speed records of the 29 long term stations as well as the monthly maximum hourly mean wind speed records of the 11 short term stations were used in the analysis using Gumbel's and Gringorten's methods. The wind speed for each station was plotted against a reduced variate by the method of order statistics (ascending order), and a straight line of best fit was drawn. The intercept and slope of these lines give the mode, $u$, and slope, $a$, of the fitted curve to the Fisher-Tippet
Type I (FT1) extreme value distribution, respectively.

A comparison between the results given by both methods was made. A relationship between the monthly maximum and the annual maxima records was developed and used for predictions of the annual maxima basic wind speeds from the monthly maximum hourly mean wind speed of the 11 short-term stations. Finally, a basic wind speed map for Oman was developed based on actual records of annual maxima and predicted annual maxima stations records.

\section{Data Analysis and Results}

Table 2 shows that the data used from the short- and long-term stations (40 stations with 6,736 records) are consistent, with very few records considered as outliers or extreme outliers based on box plot analysis. The extreme outliers have been excluded from the analysis of basic wind speed calculations. The two worst cases were $1.8 \%$ and $1.3 \%$ at Muscat International Airport and the town of Saiq, respectively. Figure 2 shows typical monthly maximum hourly mean wind speed data for Saiq from 1988-2013 based on a box plot analysis. The monthly records ranged from $5.564-21.896 \mathrm{~m} / \mathrm{s}$. This range is distributed into three areas to the left and right of the median, with each area representing 1.5 of interquartile ranges (IQR). Four records were excluded because they were considered extreme outliers.

The equations for line of best fit and basic wind speed for the 40 stations are given in Table 3 and were calculated using the Gumbel and Gringorten methods for a 50-year return period based on the monthly maximum hourly mean wind speed. It is clear that in all cases, Gumbel's method is conservative in predicting slightly larger values of basic wind speeds. The maximum and minimum differences between the two method values were $2.97 \%$ and $0.31 \%$, respectively.

Table 4 shows the equations for line of best fit and basic wind speed values for the 29 longterm stations using the Gumbel and Gringorten methods for a 50-year return period based on the annual maxima of the monthly maximum 
Table 1. Stations' years of records and elevations (names of stations are as provided by Directorate General of Civil Aviation and Meteorology).

\begin{tabular}{|c|c|c|c|}
\hline Station & Years of records & Record type & $\begin{array}{c}\text { Elevation above mean see } \\
\text { level }(\mathrm{m})\end{array}$ \\
\hline Adam & 16 & Long term & 286 \\
\hline Adam Airport & 4 & Short term & 328 \\
\hline Adam-Research & 4 & Short term & 250 \\
\hline Al Amrat & 4 & Short term & 105 \\
\hline Al Khaboura & 1 & Not considered & 35 \\
\hline Al Mudhaibi & 4 & Short term & 378 \\
\hline Bahla & 16 & Long term & 592 \\
\hline Bidiyah 3 & 4 & Short term & 316 \\
\hline Buraimi & 28 & Long term & 299 \\
\hline Buraimi New & 3 & Not considered & 372 \\
\hline Diba & 14 & Long term & 10 \\
\hline Duqum & 11 & Long term & 28 \\
\hline Duqum new & 3 & Not considered & 102 \\
\hline Fahud & 22 & Long term & 170 \\
\hline Haima & 3 & Not considered & 146 \\
\hline Ibra & 16 & Long term & 469.2 \\
\hline Ibra new & 1 & Not considered & 528 \\
\hline Ibri & 14 & Long term & 323 \\
\hline Jabal Nus & 6 & Short term & 706 \\
\hline JabalShamas & 11 & Long term & 2764 \\
\hline Joba & 11 & Long term & 34 \\
\hline Khasab Airport & 10 & Long term & 29 \\
\hline Khasab port & 28 & Long term & 4 \\
\hline Manah & 4 & Short term & 345 \\
\hline Mahdha & 1 & Not considered & 15 \\
\hline Majis & 31 & Long term & 2 \\
\hline Majis new & 3 & Not considered & 0 \\
\hline Marmul & 29 & Long term & 269 \\
\hline Masirah & 28 & Long term & 19 \\
\hline Mina salalah & 17 & Long term & 25 \\
\hline Mina sabouy 1 & 13 & Long term & 3 \\
\hline Muscat Airport & 37 & Long term & 8.4 \\
\hline Muscat new & 1 & Not considered & 12 \\
\hline New bahala & 1 & Not considered & 12 \\
\hline New samail & 1 & Not considered & 417 \\
\hline Nizwa & 15 & Long term & 462 \\
\hline Qairoon & 15 & Long term & 881 \\
\hline
\end{tabular}


A Basic Wind Speed for Oman

\begin{tabular}{lccc} 
Qalhat & 14 & Long term & 11 \\
Qarnalam & 11 & Not considered & 139 \\
Qumaira & 4 & Short term & 633 \\
Rasalhad & 9 & Long term & 43 \\
Rustaq & 16 & Long term & 322 \\
Saham & 1 & Not considered & 24 \\
Saiq & 26 & Long term & 1986 \\
Saiq new & 11 & Not considered & 1995 \\
Salalah & 28 & Long term & 23 \\
Samail & 16 & Long term & 417 \\
Sunaynah & 5 & Short term & 257 \\
Sur & 29 & Long term & 13 \\
Suwaiq & 4 & Short term & 38 \\
Thumrait & 28 & Long term & 448 \\
Um zamaim & 3 & Not considered & 126 \\
Wave rider & 0 & Not considered & 0 \\
Yalooni & 15 & Long term & 156 \\
Yalooni Airport & & Not considered & 172.3 \\
"Ajais" & 2 & & \\
& & & \\
\hline
\end{tabular}

Table 2. Outliers and extreme outliers of wind speed data for long- and short-term stations.

\begin{tabular}{lcccc}
\hline & Station & No. of records & Outliers & Extreme outliers \\
\hline 1 & Adam & 120 & 5 & 1 \\
2 & Adam Airport & 89 & none & none \\
3 & Al Amrat & 45 & 1 & none \\
4 & Al Mudhaibi & 39 & none & none \\
5 & Bahla & 185 & none & none \\
6 & Bidiyah & 288 & none & 1 \\
7 & Buraimi & 153 & 2 & 1 \\
8 & Diba & 115 & 1 & none \\
9 & Duqum & 58 & 3 & none \\
10 & Duqum new & 178 & none & none \\
11 & Fahud & 182 & 4 & none \\
12 & Ibra & 139 & 1 & none \\
13 & Ibri & 59 & none & none \\
14 & Jabal Nus & 118 & 1 & none \\
15 & Jabal Shams & 123 & 5 & none \\
16 & Joba & 105 & none & none \\
17 & Khasab Airport & 246 & none & none \\
18 & Khasab Port & 365 & 2 & none \\
19 & Majis & 261 & 5 & 1 \\
20 & Marmul & & 4 & none
\end{tabular}


A.S. Alnuaimi, M.A. Mohsin and K.H. Al-Riyami

\begin{tabular}{|c|c|c|c|c|}
\hline 21 & Masirah & 335 & 5 & 3 \\
\hline 22 & Mina Salalah & 182 & 6 & 1 \\
\hline 23 & Mina Sa bouy 1 & 124 & 1 & none \\
\hline 24 & Muscat Airport & 442 & 15 & 8 \\
\hline 25 & Nizwa & 174 & 2 & none \\
\hline 26 & Qairoon & 168 & 4 & none \\
\hline 27 & Qalhat & 166 & 1 & none \\
\hline 28 & Qaranalam & 93 & 1 & none \\
\hline 29 & Qumaira & 37 & 1 & none \\
\hline 30 & Ras Al Haad & 93 & none & 2 \\
\hline 31 & Rustaq & 184 & 7 & 2 \\
\hline 32 & Saiq & 311 & 2 & 4 \\
\hline 33 & Saiq new & 111 & 3 & 2 \\
\hline 34 & Salalah & 335 & 13 & 1 \\
\hline 35 & Samail & 187 & 5 & 1 \\
\hline 36 & Sunaynah & 50 & 1 & none \\
\hline 37 & Sur & 331 & 2 & none \\
\hline 38 & Suwaiq & 45 & 1 & none \\
\hline 39 & Thumrait & 336 & none & none \\
\hline 40 & Yalooni & 120 & 3 & none \\
\hline
\end{tabular}

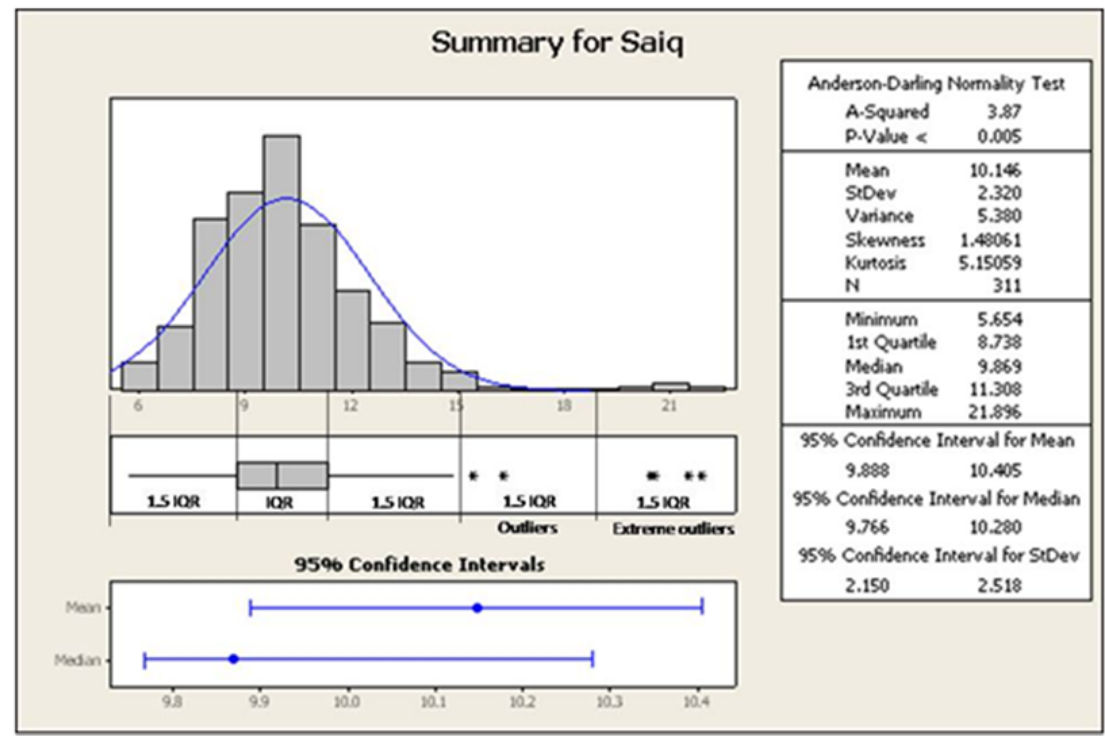

Figure 2. Monthly maximum wind speed for Saiq (1988 - 2013). 
hourly mean wind speed. Again, Gumbel's method predicted slightly larger values for basic wind speed. The maximum and minimum differences between the two method values were $7.58 \%$ and $1.85 \%$, respectively. Gumbel's method was considered for further assessment and a comparison between the annual maxima and the monthly maximum basic wind speeds of the 29 long-term stations.

Due to a lack of long-term records in some regions of Oman, the monthly maximum basic wind speed from the short-term stations was used to predict the long-term basic wind speed in those areas using Eqn. 5.

$\mathrm{V}_{\mathrm{b}(\text { annual })}=0.76+1.21 \mathrm{~V}_{\mathrm{b}(\text { monthly })}$

$\mathrm{R}^{2}=0.665$

where,

$\mathrm{V}_{\mathrm{b} \text { (monthly) }}=$ basic wind speed based on monthly maximum hourly-mean $(\mathrm{m} / \mathrm{s})$.

$\mathrm{V}_{\mathrm{b} \text { (annual) }}=$ predicted annual basic wind speed (m/s).

In the coefficient of correlation for Eqn. 5, $\mathrm{R}^{2}$ (0.665) shows an acceptable degree of correlation. Furthermore, analysis of variance (ANOVA) for Eqn. 5 resulted in a satisfactory hypothesis with $P$ value $=0.000$ for the given $\mathrm{F}$ value (53.59) as shown in Table 5. Therefore, Equation 5 can be used as a conversion factor in the 11 short-term stations.

Table 6 shows the 50-year return period for predicted basic wind speed of the 29 long-term stations based on actual annual maxima of the monthly maximum hourly-mean wind speed as well as for the 11 short-term stations using Eqn. 5.Return periods for 100 years or more (implying a low-risk level) may have to be extrapolated for exceptionally important structures, such as nuclear power reactors and satellite communication towers. Extrapolations of basic wind speed to higher return periods of more than 50 years for ultimate limit state design have not been carried out in this research due to the limitation of historical records, which are generally less than 37 years old.

\section{Basic Wind Speed Map}

The basic wind speed values contained in Table 6 were used to develop a basic wind speed map of Oman using the largest reading in each nearby groups of values as shown in Fig. 3. As expected, the coastal regions of Oman recorded basic wind speed values higher than the interior regions due to the presence of the $\mathrm{Al}$ Hajer Mountains and the reduction of wind speed over the land. This is more pronounced in the Musandam Region in Oman's far north where the basic wind speed dropped from 21 meters/second (m/s) in Diba to $16 \mathrm{~m} / \mathrm{s}$ in Khasab. The basic wind speed values ranged from $16 \mathrm{~m} / \mathrm{s}$ in Khasab, which is surrounded by tall mountains, to $31 \mathrm{~m} / \mathrm{s}$ in Masirah, which borders the Indian Ocean.

It is assumed that the basic wind speed at any location in the country will fall within the range of $16-31 \mathrm{~m} / \mathrm{s}$. This implies that for areas in the interior," basic wind speeds that do not exactly fit in any given value(Fig. 3) should be assigned to the nearest higher level value due to similarity in topography and the absence of wind barriers such as mountains.

It is worth mentioning that this research has developed basic wind speeds based on hourlymean raw data which is in line with the BS63992 procedure, superseding the previous method of CP3: Chapter 5-Part 2, which used the threesecond gust which as is (Al Maawali et al. 2008).

\section{Conclusion and Recommendations}

\subsection{Conclusion}

Hourly mean wind speed records were obtained from 55 metrological stations in Oman, and 40 stations with at least four continuous years of records were used in the calculation of basic wind speeds. The monthly maximum and the annual maxima of the hourly mean were used in the analysis using Gumbel and Gringorten's methods. It was found that Gumbel's method predicted slightly larger values of basic wind speed than Gringorten's. The maximum and minimum differences between the two method values were 2.97 and $0.31 \%$, respectively, in the case of monthly maximum hourly mean and 7.58 and $1.85 \%$, 
Table 3. Linear best-fit equations for the 40 stations (monthly maximum hourly-mean).

\begin{tabular}{|c|c|c|c|c|c|}
\hline Station & Gumbel Method & $\begin{array}{l}\text { Gringorten } \\
\text { Method }\end{array}$ & $\begin{array}{l}\text { Gumbel } \\
\text { Method }\end{array}$ & $\begin{array}{l}\text { Gringorten } \\
\text { Method }\end{array}$ & $\%$ difference \\
\hline Adam & $1.3746 x+8.7355$ & $1.3396 x+8.7451$ & 14.11 & 13.98 & 0.91 \\
\hline Adam Airport & $2.0007 x+10.832$ & $1.8699 x+10.864$ & 18.65 & 18.17 & 2.66 \\
\hline Al Amrat & $0.8782 x+6.5392$ & $0.8295 x+6.5485$ & 9.97 & 9.79 & 1.87 \\
\hline Al Mudhaibi & $0.7689 x+6.5824$ & $0.7467 x+6.5899$ & 9.59 & 9.51 & 0.83 \\
\hline Bahla & $1.2814 x+6.4704$ & $1.244 x+6.4818$ & 11.48 & 11.35 & 1.18 \\
\hline Bidiyah & $1.8098 x+8.8109$ & $1.7025 x+8.8335$ & 15.89 & 15.49 & 2.55 \\
\hline Buraimi & $1.4081 x+8.3545$ & $1.3784 x+8.3637$ & 13.86 & 13.75 & 0.79 \\
\hline Diba & $1.8632 x+8.1027$ & $1.8033 x+8.1203$ & 15.39 & 15.17 & 1.43 \\
\hline Duqum & $2.6691 x+10.336$ & $2.567 x+10.365$ & 20.77 & 20.40 & 1.81 \\
\hline Duqum New & $3.0118 x+11.723$ & $2.8262 x+11.775$ & 23.50 & 22.82 & 2.97 \\
\hline Fahud & $2.062 x+11.224$ & $2.002 x+11.242$ & 19.29 & 19.07 & 1.13 \\
\hline Ibra & $1.4357 x+7.3221$ & $1.3959 x+7.3334$ & 12.94 & 12.79 & 1.14 \\
\hline Ibri & $1.4215 x+10.662$ & $1.3705 x+10.677$ & 16.22 & 16.03 & 1.18 \\
\hline Jabal Nus & $2.4533 x+11.995$ & $2.2907 x+12.044$ & 21.59 & 21.00 & 2.80 \\
\hline Jabal Shams & $2.6081 x+12.833$ & $2.5159 x+12.857$ & 23.03 & 22.69 & 1.52 \\
\hline Joba & $1.5454 x+11.19$ & $1.485 x+11.208$ & 17.23 & 17.01 & 1.32 \\
\hline Khasab Airport & $0.8294 x+8.1281$ & $0.7926 x+8.1394$ & 11.37 & 11.24 & 1.19 \\
\hline Khasab Port & $1.3584 x+9.1348$ & $1.3261 x+9.1447$ & 14.45 & 14.33 & 0.80 \\
\hline Majis & $1.7366 x+7.9534$ & $1.7104 x+7.9604$ & 14.74 & 14.65 & 0.65 \\
\hline Marmul & $2.2194 x+11.472$ & $2.1729 x+11.486$ & 20.15 & 19.98 & 0.87 \\
\hline Masirah & $2.0096 x+10.386$ & $1.9926 x+10.391$ & 18.24 & 18.18 & 0.31 \\
\hline Mina Salalah & $2.4491 x+6.5257$ & $2.3894 x+6.5406$ & 16.11 & 15.89 & 1.38 \\
\hline MinaSabouy 1 & $1.3665 x+7.4038$ & $1.3165 x+7.4181$ & 12.75 & 12.57 & 1.44 \\
\hline Muscat Airport & $2.743 x+8.7434$ & $2.7187 x+8.7464$ & 19.47 & 19.38 & 0.49 \\
\hline Nizwa & $1.6017 x+8.4896$ & $1.5528 x+8.5046$ & 14.75 & 14.58 & 1.21 \\
\hline Qairoon & $2.6519 x+11.215$ & $2.579 x+11.235$ & 21.59 & 21.32 & 1.25 \\
\hline Qalhat & $1.9233 x+10.277$ & $1.8677 x+10.293$ & 17.80 & 17.60 & 1.14 \\
\hline Qumaira & $1.7374 x+11.369$ & $1.6592 x+11.392$ & 17.80 & 17.60 & 1.14 \\
\hline QaranAalam & $1.7374 x+11.369$ & $1.7374 x+11.369$ & 18.17 & 17.88 & 1.58 \\
\hline Ras Al Haad & $1.5294 x+11.476$ & $1.4585 x+11.497$ & 17.46 & 17.20 & 1.49 \\
\hline Rustaq & $1.5368 x+5.5871$ & $1.501 x+5.5956$ & 11.60 & 11.47 & 1.15 \\
\hline Saiq & $1.5533 x+9.1184$ & $1.5212 x+9.1286$ & 15.19 & 15.08 & 0.77 \\
\hline Saiq New & $1.7909 x+8.8229$ & $1.7205 x+8.8426$ & 15.83 & 15.57 & 1.64 \\
\hline Salalah & $1.8437 x+8.224$ & $1.8128 x+8.2326$ & 15.44 & 15.32 & 0.73 \\
\hline Samail & $1.1133 x+6.9427$ & $1.0842 x+6.9508$ & 11.30 & 11.20 & 0.87 \\
\hline Sunaynah & $1.5861 x+11.034$ & $1.4863 x+11.06$ & 17.24 & 16.87 & 2.16 \\
\hline Sur & $2.4025 x+12.569$ & $2.3549 x+12.584$ & 21.97 & 21.80 & 0.79 \\
\hline Suwaiq & $0.9255 x+7.9023$ & $0.8663 x+7.9165$ & 11.52 & 11.31 & 1.92 \\
\hline Thumrait & $4.4675 x+22.839$ & $4.374 x+22.87$ & 20.72 & 20.50 & 1.08 \\
\hline Yalooni & $1 x+12.694$ & $0.8671 x+12.728$ & 15.68 & 15.47 & 1.34 \\
\hline
\end{tabular}


Table 4. Linear best-fit equations for the 29 long-term stations (annual maxima of the monthly maximum hourly-mean).

\begin{tabular}{|c|c|c|c|c|c|}
\hline Station & Gumbel Method & $\begin{array}{c}\text { Gringorten } \\
\text { Method }\end{array}$ & $\begin{array}{l}\text { Gumbel } \\
\text { Method }\end{array}$ & $\begin{array}{c}\text { Gringorten } \\
\text { Method }\end{array}$ & $\begin{array}{c}\% \\
\text { difference }\end{array}$ \\
\hline Adam & $y=1.715 x+11.59$ & $y=1.595 x+11.63$ & 18.30 & 17.87 & 2.40 \\
\hline Bahla & $y=0.848 x+9.460$ & $y=0.748 x+9.483$ & 12.78 & 12.41 & 2.97 \\
\hline Buraimi & $y=1.201 x+11.38$ & $y=1.092 x+11.41$ & 16.08 & 15.68 & 2.53 \\
\hline Diba & $y=1.624 x+12.19$ & $y=1.421 x+12.24$ & 18.54 & 17.80 & 4.18 \\
\hline Duqum & $y=3.512 x+13.74$ & $y=2.981 x+13.88$ & 27.48 & 25.54 & 7.58 \\
\hline Fahud & $y=1.413 x+15.79$ & $y=1.289 x+15.82$ & 21.32 & 20.86 & 2.18 \\
\hline Ibra & $y=1.325 x+10.46$ & $y=1.180 x+10.49$ & 15.64 & 15.11 & 3.56 \\
\hline Ibri & $y=1.542 x+12.89$ & $y=1.331 x+12.94$ & 18.92 & 18.15 & 4.27 \\
\hline Jabal Shams & $y=2.967 x+18.12$ & $y=2.513 x+18.24$ & 29.73 & 28.07 & 5.90 \\
\hline Joba & $y=0.918 x+14.63$ & $y=0.780 x+14.66$ & 18.22 & 17.71 & 2.88 \\
\hline Khasab Airport & $y=0.644 x+9.708$ & $y=0.541 x+9.735$ & 12.23 & 11.85 & 3.17 \\
\hline Khasab Port & $y=0.904 x+12.29$ & $y=0.825 x+12.30$ & 15.83 & 15.53 & 1.93 \\
\hline Majis & $y=2.378 x+11.39$ & $y=2.190 x+11.43$ & 20.69 & 20.00 & 3.48 \\
\hline Marmul & $y=2.311 x+15.28$ & $y=2.124 x+15.32$ & 24.32 & 23.63 & 2.93 \\
\hline Masirah & $y=4.100 x+15.05$ & $y=3.789 x+15.11$ & 31.09 & 29.93 & 3.86 \\
\hline Mina Salalah & $y=2.567 x+12$ & $y=2.310 x+12.07$ & 22.06 & 21.11 & 4.53 \\
\hline Mina Sabouy 1 & $y=1.345 x+10.16$ & $y=1.160 x+10$ & 15.42 & 14.74 & 4.64 \\
\hline Muscat Airport & $y=4.555 x+12.08$ & $y=4.268 x+12.13$ & 29.90 & 28.83 & 3.72 \\
\hline Nizwa & $y=1.091 x+12.17$ & $y=0.959 x+12.20$ & 16.44 & 15.95 & 3.05 \\
\hline Qairoon & $y=2.209 x+13.98$ & $y=1.925 x+14.05$ & 22.62 & 21.58 & 4.82 \\
\hline Qalhat & $y=1.614 x+15.22$ & $y=1.420 x+15.27$ & 21.53 & 20.83 & 3.40 \\
\hline Ras Al Haad & $y=2.898 x+14.62$ & $y=2.486 x+14.70$ & 25.96 & 24.43 & 6.27 \\
\hline Rustaq & $y=1.672 x+9.103$ & $y=1.503 x+9.134$ & 15.64 & 15.01 & 4.20 \\
\hline Saiq & $y=2.509 x+13.54$ & $y=2.286 x+13.59$ & 23.36 & 22.53 & 3.65 \\
\hline Salalah & $y=1.909 x+13.12$ & $y=1.743 x+13.16$ & 20.59 & 19.98 & 3.05 \\
\hline Samail & $y=2.083 x+9.659$ & $y=1.866 x+9.701$ & 17.81 & 17.00 & 4.75 \\
\hline Sur & $y=1.848 x+17.59$ & $y=1.685 x+17.63$ & 24.82 & 24.22 & 2.47 \\
\hline Thumrait & $y=1.741 x+17.17$ & $y=1.627 x+17.18$ & 23.98 & 23.54 & 1.85 \\
\hline Yalooni & $y=1 x+12.69$ & $y=0.867 x+12.72$ & 16.60 & 16.11 & 3.04 \\
\hline
\end{tabular}

Table 5. Analysis of Variance for Equation 5.

\begin{tabular}{|c|c|c|c|c|c|}
\hline Source & DF & SS & MS & $\mathbf{F}$ & p-value \\
\hline Regression & 1 & 481.30 & 481.30 & 53.59 & 0.000 \\
\hline Regression error & 27 & 242.47 & 8.98 & & \\
\hline Total & 28 & 723.77 & & & \\
\hline
\end{tabular}

$\mathrm{DF}=$ the degrees of freedom in the source

SS $=$ the sum of squares due to the source

MS = the mean sum of squares due to the source

$\mathrm{F}=$ calculated $\mathrm{F}$ value (MS $\mathrm{Megression} / \mathrm{MS}_{\text {Errors }}$ )

p-value = the probability of obtaining a test statistic at least as extreme as the one that was actually observed, assuming that the null hypothesis is true. 
Table 6. Basic wind speed for 50-year return period based on annual maxima of monthly maximum hourly-mean.

\begin{tabular}{lc}
\hline Station & Basic wind speed 50-year return period \\
\hline Adam & 18.30 \\
Adam Airport & $23.33^{*}$ \\
Al Amrat & $12.82^{*}$ \\
Al Mudhaibi & $12.36^{*}$ \\
Bahla & 12.78 \\
Bidiyah & $19.99^{*}$ \\
Buraimi & 16.08 \\
Diba & 18.54 \\
Duqum & 27.48 \\
Duqum New & $29.20^{*}$ \\
Fahud & 21.32 \\
Ibra & 15.64 \\
Ibri & 18.92 \\
Jabal Nus & $26.88^{*}$ \\
Jabal Shams & 29.73 \\
Joba & 18.22 \\
Khasab Airport & 12.23 \\
Khasab Port & 15.83 \\
Majis & 20.69 \\
Marmul & 24.32 \\
Masirah & 31.09 \\
Mina Salalah & 22.06 \\
MinaSabouy 1 & 15.42 \\
Muscat Airport & 29.90 \\
Nizwa & 16.44 \\
Qairoon & 22.62 \\
Qalhat & 21.53 \\
Qumaira & $22.30^{*}$ \\
QaranAalam & $22.75^{*}$ \\
Ras Al Haad & 25.96 \\
Rustaq & 15.64 \\
Saiq & 23.36 \\
Saiq New & $19.91^{*}$ \\
Salalah & 20.59 \\
Samail & 17.81 \\
Sunaynah & $21.62^{*}$ \\
Sur & 24.82 \\
Suwaiq & $14.70^{*}$ \\
Thumrait & \\
\hline Yalooni & \\
\hline & \\
\hline
\end{tabular}

*Predicted using Equation 5 


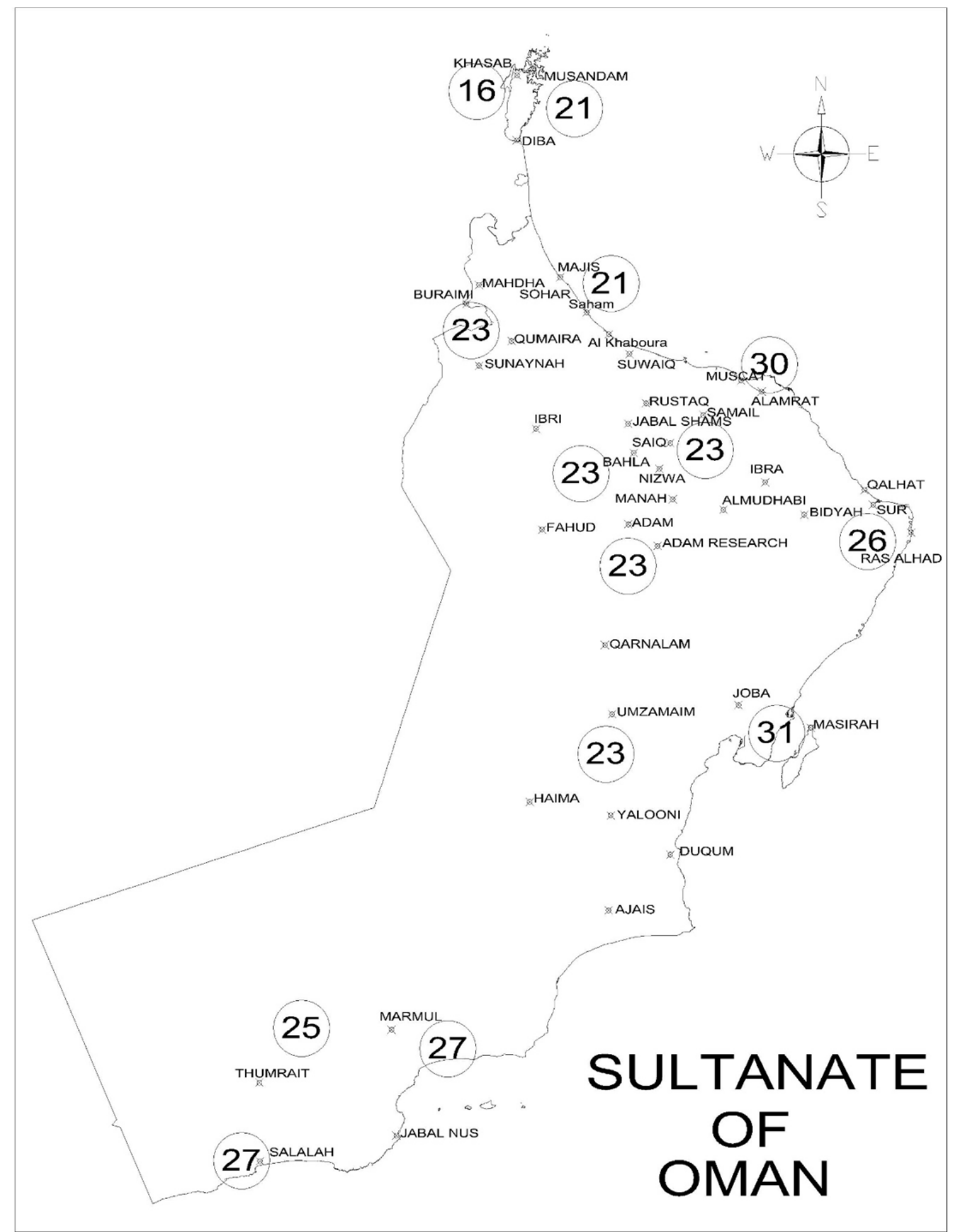

Figure 3. Basic wind speed map. 
respectively, in the case of annual maxima. Due to the lack of long-term records in some regions of Oman, the monthly maximum basic wind speed from the short-term stations was used to predict long-term basic wind speed. Accordingly, a basic wind speed map was developed for the 50-year return period using the basic wind speed from 29 stations with at least nine continuous years of records based on actual annual maxima as well as predicted annual maxima basic wind speed for 11 stations with 4-8 continuous years of records. The basic wind speed values ranged from $16 \mathrm{~m} / \mathrm{s}$ to $31 \mathrm{~m} / \mathrm{s}$.

\subsection{Recommendations}

- The basic wind speed map developed in this research is recommended for use as a guide for structural design in Oman.

- For future research, results from different Gulf Cooperative Council (GCC) countries and Yemen are compiled and a regional basic wind speed map is developed.

- Further analysis of future wind speed data need to be carried out every five years.

- Special analysis of recent odd readings, such as those that resulted from Cyclones Gonu and Phet, should be made if such events recur frequently enough to establish records.

\section{Acknowledgment}

The authors are indebted to the Directorate General of Civil Aviation and Meteorology under the Ministry of Transportation and Telecommunication for the provision of the data used in this research. The data included station names, locations and hourly mean wind speeds. The concerned staff's cooperation is gratefully acknowledged and appreciated.

\section{References}

Abohemda MB, Al Shebani MM (2010), Wind load characteristics in Libya, World Academy of Science, Engineering and Technology 63:240-243.

Akosy H, Toprak ZF, Aytek A, Unal NE (2004), Stochastic generation of hourly mean wind speed data. Renewable Energy, Elsevier 29:2111-2131.

Al Maawli SS, Majid TA, Yahya AS (2008),
Determination of basic wind speed for building structures in Oman. Proceedings of International Conference on Construction and Building Technology, ICCBT'08, F(22):235-244.

American Society of Civil Engineers (ASCE) (1991), Guidelines for electrical transmission line structural loadings, 1801 Alexander Bell Drive, Reston, Virginia 20191, USA.

An Y, Pandy M (2005), A comparison of methods of extreme wind speed estimation. Journal Wind Engineering and Industrial Aerodynamics, Elsevier 93:535-545.

BS 6399-2: (1997), Loading for buildings part 2. Code of Practice for wind loads. British Standard Institution, London.

Choi E, Tanurdjaja A (2002), Extreme wind studies in Singapore, an area with mixed weather system. Journal Wind Engineering and Industrial Aerodynamics, Elsevier 90:1611-1630.

Dorvlo ASS (2002), Estimating wind speed distribution. Energy Conversion and Management. Pergamon 43:311-2318.

Dyrbye, C, Hansen SO (1999), Wind loads on structures. John Wiley \& Sons.

Gibbs T, Browne H, Rocheford B (1981), Code of practice for wind loads for Structural Design. BNS-CP28, sponsored by the Organization of American States, the National Council for Science and Technology and the Barbados Association of Professional Engineers.

Grigoriu M (1984), Estimation of extreme winds from short records. Journal of Structural Engineering ASCE 110(7):1467-1484.

Gringorten I (1963), A plotting rule for extreme probability paper. Journal of Geophysical Research 68(3):813-814.

Gumbel EJ (1958), Statistics of extreme, Colombia University press. New York, NYC, USA.

Harris RI (1996), Gumbel re-visited - a new look at extreme value statistics applied to wind speeds. Journal Wind Engineering and Industrial Aerodynamics 59: 1-22.

Holmes J (2001), Wind loading of structures, SPON press.

Kasperski M (2002), A new wind zone map of Germany.Journal Wind Engineering and Industrial Aerodynamics 90:1271-1287.

Kishor CM, Delahay J (2004), Guide to the use of the wind load provisions of ASCE 7-02, 140, 
ASCE Press.

Kramer C, Gerhardt HJ (1988), Advances in Civil Engineering, Part 1:8, Elsevier Science Publishing Company, 665 Avenue of the Americas, New York, USA.

Lakshmanan N, Gomathinayagam S, Harikrishna P, Abraham A, Ganapathi SC (2009), Basic wind speed map of India with long-term hourly wind data. Currant Science 96(7):911-922.

Minimum Design Loads for Buildings and Other Structures ASCE/SEI-7-10 (2010), American society of civil engineers and the structural engineering institute. ASCE Standard, 1801 Alexander Bell Drive, Reston, Virginia 20191, USA.

Ministry of Transportation and Tele - communication (2014), Directorate General of Civil Aviation and Meteorology - Oman, Annual report.

Sahin A (2003), Hourly wind velocity exceedance maps of Turkey. Energy Conversion and Management 44:549-557.

Simiu E (2009), Wind loading codification in the Americas. Fundamentals for a Renewal, $11^{\text {th }}$ Americas Conference on Wind Engineering, San Juan, PR, USA.

Simiu E, Filliben JJ, Shaver JR (1982), Short-term records and extreme wind speeds. Journal of Structural Division ASCE 108(11):2571-2577.

Simiu E, Heckert N, Filliben J, Johnson S (2001), Extreme wind load estimates based on the Gumbel distribution of dynamic pressures: an assessment. Structural Safety 23:221-229. 